\title{
Alimentação infantil no primeiro ano de vida
}

\author{
Luana Miranda da Silveira*, Marlene Azevedo Magalhães Monteiro, D.Sc.**
}

*Enfermeira, Especialista em Formação Pedagógica para Profissionais de Saúde pela Universidade Federal de Minas Gerais (UFMG), Hospital Bom Jesus, Congonhas - MG, ${ }^{* *}$ Nutricionista, Departamento de Nutrição, Escola de Enfermagem, Universidade Federal de Minas Gerais (UFMG)

\section{Resumo}

O presente estudo tem como objetivo analisar as orientaçóes sobre a alimentaçáo infantil para crianças no primeiro ano de vida e a contribuição das práticas educativas dos profissionais de saúde. Foi realizada uma revisão integrativa baseada em levantamento bibliográfico com publicaçôes entre 2002 e 2012 composta de 17 artigos. As bases de dados utilizadas foram Scielo, Medline, Lilacs e Ceres: Nutrição \& Saúde - UERJ. Dentre os estudos selecionados, 58,8\% dos autores eram nutricionistas, procedentes grande parte do Sudeste $(70,5 \%)$ e a maioria com titulação de doutorado $(53,0 \%)$. Quanto ao tipo de pesquisa, os artigos mais utilizados foram $(94,1 \%)$ comparados às dissertaçóes $(5,9 \%)$, bem como os com delineamento quanti-qualitativo $(35,2 \%)$. Houve grande diversificação de instrumentos para a coleta de dados. Observou-se também que os objetivos se mostraram claros em relação ao proposto e, por meio deles, foram geradas quatro temáticas que foram discutidas de acordo com os resultados, conclusões e recomendaçōes de cada autor dos estudos selecionados. Concluiu-se que para alcançar uma alimentação infantil saudável é necessário, por parte dos profissionais de saúde, o reconhecimento dos aspectos simbólicos e culturais da alimentação infantil, permitindo maior proximidade entre o profissional de saúde e os cuidadores da criança.

Palavras-chave: saúde da criança, nutrição do lactente, educação em saúde.

\section{Abstract}

\section{Infant feeding in the first year of life}

The present study aimed to analyze the guidelines on infant feeding of the first year of children's life and the contribution of health professionals through educational practices. An integrative review based on bibliographic publications between 2002 and 2012 was performed, using Scielo, Medline, Lilacs and Ceres: Health \& Nutrition - UERJ data bases, with a final sample of 17 studies. Among the selected studies, 58.8\% authors were nutritionists, most of them from southeast of Brazil (70.5\%) and the majority with doctoral degree (53.0\%). Regarding the type of research, articles have been most frequently used (94.1\%) compared to dissertations (5.9\%), as well as with quantitative and qualitative research design $(35.2 \%)$. There was a variety of types of data collection instruments. It was also observed that the aims were clear and, through them, four themes, which were discussed according to the results, conclusions and recommendations of each author of the selected studies were generated. We concluded that to achieve a healthy infant feeding health professionals 
should recognize the symbolic and cultural aspects of infant feeding, allowing proximity between the health professional and caregivers.

Key-words: children's health, infant nutrition, health education.

\section{Resumen}

\section{Alimentación infantil en el primer año de vida}

El objetivo del estudio fue analizar las orientaciones sobre alimentación infantil para niños durante el primer año de vida y la contribución de los profesionales de la salud a través de prácticas educativas. Una revisión integrativa basada en una búsqueda bibliográfica ha sido realizada, entre los años de 2002 y 2012, en las bases de datos Scielo, Medline, Lilacs e Ceres: Nutrição \& Saúde - UERJ, compuesta de 17 estudios. Entre los estudios seleccionados, 58,8\% de los autores eran nutricionistas, gran parte procedente del Sudeste $(70,5 \%)$ y la mayoría con titulación de doctorado $(53,0 \%)$. Con respecto a la investigación, los artículos más utilizados fueron (94,1\%) comparados a las disertaciones $(5,9 \%)$, así como los diseńos cuanti-cualitativos $(35,2 \%)$. Hubo una variedad de instrumentos para la colecta de datos. Se observó también que los objetivos se mostraron claros en relación a lo propuesto y, tras ellos, surgieron cuatro temáticas que fueron discutidas de acuerdo a los resultados, conclusiones y recomendaciones de cada autor de los estudios seleccionados. Se ha concluido que para lograr una alimentación saludable es necesario, por parte de los profesionales de la salud, el reconocimiento de los aspectos simbólicos y culturales de la alimentación infantil, permitiendo mayor proximidad entre el profesional de salud y los cuidadores del niño.

Palabras-clave: salud del niño, nutrición del lactante, educación en salud.

\section{Introdução}

A amamentação exclusiva até o sexto mês de vida é a melhor forma de alimentar o lactente, visto que hoje há um acordo mundial de que nenhum benefício supera os riscos e os prejuízos da introdução precoce de alimentos adicionais [1]. A partir do sexto mês de vida, a alimentação deve complementar os numerosos benefícios e funçóes do leite materno, que deve ser oferecido até dois anos de idade ou mais. Os alimentos complementares, a partir dessa idade, além de contribuir com o estado nutricional da criança, permitem um maior contato da criança com o seu cuidador e com a variedade de sabores, cores, aromas e texturas que lhe são apresentados [2].

Alimentaçáo complementar é definida como a oferta de outros alimentos ou líquidos à criança, em adição ao leite materno. Os alimentos complementares podem ser preparados especialmente para as crianças ou consumidos pelos demais membros da família, modificados para atender as habilidades e necessidades da criança [3].

Além disso, a partir do sexto mês a inclusão na dieta de alimentos complementares disponíveis na unidade familiar é o esquema recomendado pela Organizaçáo Mundial de Saúde (OMS) para as crianças de todo o mundo. Após essa idade, a inclusão destes alimentos tem o objetivo de elevar, principalmente, as cotas de energia e micronutrientes [4].

Nesse sentido, a adequação nutricional dos alimentos complementares é fundamental na prevenção de morbimortalidade na infância, como nos casos de desnutrição e sobrepeso. O déficit de crescimento linear adquirido cedo na infância é difícil de ser revertido após os dois anos. Nesse contexto, atingir a alimentação ótima para a maioria das crianças pequenas deve ser um componente essencial da estratégia global para a segurança alimentar de uma população [5].

Em casos excepcionais de desmame precoce não revertido ou em situações em que a mãe é soropositiva para o vírus HIV, a alimentação também deve ser trabalhada de modo a incentivar à mãe a oferecer para a criança a alimentação láctea, por meio da oferta do leite humano pasteurizado proveniente do Banco de Leite Humano, quando disponível [2].

É importante lembrar que o sucesso da promoção da nutrição infantil vai depender da praticidade dos pais, que desenvolvem o papel dos primeiros educadores nutricionais. Para isso, é essencial o conhecimento dos conceitos e opinióes dos responsáveis pela criança sobre a alimentação das mesmas; reconhecimento e valorização pelo 
profissional de saúde, inclusive, ajudando à mãe a executar as práticas de alimentação da criança até que ela aprenda a fazê-las sozinha [5].

É nesse contexto que também emerge a concepção da promoção das práticas alimentares saudáveis, na qual a alimentação tem sido colocada como uma das estratégias para a promoção da saúde. Não parece haver dúvidas sobre a importância da educação alimentar e nutricional no consumo alimentar adequado, no entanto as reflexóes sobre suas possibilidades e limites, como também o modo como ela é concebida, ainda são escassas [6].

Diante do exposto, a pergunta norteadora deste trabalho é: "Qual a contribuição das práticas educativas sobre a alimentação infantil no primeiro ano de vida?". Tendo como objetivo geral analisar a alimentação infantil oferecida às crianças no primeiro ano de vida e a contribuiçáo das práticas educativas dos profissionais de saúde.

\section{Material e métodos}

Este estudo trata-se de uma revisão integrativa da literatura com o propósito de reunir e sintetizar o conhecimento pré-existente sobre a temática proposta. De acordo com Polit, Beck e Hungler [7], a revisão integrativa sumariza as pesquisas realizadas sobre determinado assunto construindo uma conclusão a partir de muitos estudos realizados separadamente, mas que investigam problemas idênticos ou similares. Os estudos são analisados de forma sistemática em relação aos seus objetivos, materiais e métodos, permitindo dessa forma que o leitor analise o conhecimento sobre o tema abordado.

O propósito primário de uma revisão integrativa é mergulhar no entendimento de determinado fenômeno e isto é fundamental no desenvolvimento conceitual próprio do mesmo, uma vez que a elaboração da revisão é sobre conhecimento já produzido e acarreta a identificação de possíveis lacunas [8].

$\mathrm{Na}$ construção da revisão integrativa é importante percorrer as seis etapas metodológicas distintas, conforme Ganong (1987): Primeira etapa: identificação ou seleção do tema e elaboração da pergunta norteadora. Segunda etapa: coleta de dados, estabelecimento de critérios para inclusão e exclusão de estudos. Terceira etapa: definição das informações a serem extraídas dos estudos selecionados/ categorização dos estudos. É necessária a utilização de um instrumento previamente elaborado. Quarta etapa: avaliação dos estudos incluídos na revisão integrativa. Quinta etapa: interpretação dos resultados ou discussão dos resultados. Sexta etapa: apresentação da revisão integrativa.

\section{Populaçáo e amostra}

Realizou-se a investigação do tema mediante levantamento bibliográfico em livros, periódicos, dissertaçóes que atendiam ao objetivo do estudo, além de busca digital em banco de dados eletrônicos.

Foram pesquisados artigos em revistas científicas disponíveis na internet, nas bases de dados Scientific Electronic Library Online (Scielo), Medical Literature Analysis and Retrieval Sistem (Medline), Literatura Latino-Americana e do Caribe em Ciências da Saúde (Lilacs) e Ceres: Nutrição \& Saúde - UERJ, utilizando-se os seguintes descritores: alimentação infantil; nutrição infantil; atuação do enfermeiro; aleitamento materno; educação em saúde; enfermagem; saúde da mulher; enfermagem pediátrica e educação em saúde. Também foram considerados dados compilados do Ministério da Saúde.

$\mathrm{Na}$ busca eletrônica foram obtidas 03 dissertaçóes e 53 artigos completos dos quais foram selecionados 01 dissertaçáo e 16 artigos que possuíam seus textos completos com indexação no Scielo, Lilacs, Medline e Ceres: Nutrição \& Saúde - UERJ (Quadro I). As duas dissertaçóes e os outros 37 artigos não foram utilizados, pois os conteúdos dos mesmos não estavam totalmente relacionados com o tema deste estudo.

Os critérios de inclusão definidos para a seleção dos artigos foram: artigos publicados em português, artigos na íntegra que retratassem a temática, publicados e indexados nos referidos bancos de dados nos últimos onze anos.

\section{Variáveis de estudo}

Neste estudo foram selecionadas as variáveis: profissão, área de atuação, país de origem, qualificação, fonte, ano de publicação, periódico, tipo de publicação, delineamento, nível de evidência relacionada ao problema de estudo.

\section{Instrumentos de coleta de dados}

Para a coleta de dados dos artigos incluídos na revisão integrativa foi utilizado o instrumen- 
to elaborado por Campos [9]. Este instrumento foi construído em sua dissertação de mestrado, contendo título de publicação, autoria, dados da publicação, metodologia e objetivos. A elaboração do instrumento de coleta de dados tem com objetivo reunir as informaçóes-chave de cada artigo selecionado [10].

A tarefa de definir quais serão as características ou informaçóes que serão coletadas dos estudos é a essência da revisáo integrativa, sendo essa fase análoga à coleta de qualquer pesquisa [11].

\section{Análise dos dados}

Os estudos selecionados foram analisados detalhadamente. A análise foi realizada de forma crítica, procurando explicaçóes para os resultados diferentes ou conflitantes nas diferentes pesquisas.

\section{Resultados e discussão}

\section{Caracterizaçáo dos estudos selecionados}

No Quadro 1 está relacionado o total de publicaçôes encontradas, pré-selecionadas, excluídas e incluídas, a partir da estratégia de busca em cada base de dados.

Quadro 1 - Número de estudos encontrados, pré-selecionados, excluídos e incluídos, de acordo com as bases de dados eletrônicas.

\begin{tabular}{|l|c|c|c|c|}
\hline Base de dados & $\begin{array}{c}\text { Estudos } \\
\text { encon- } \\
\text { trados }\end{array}$ & $\begin{array}{c}\text { Estudos } \\
\text { pré-se- } \\
\text { lecio- } \\
\text { nados }\end{array}$ & $\begin{array}{c}\text { Estudos } \\
\text { excluí- } \\
\text { dos }\end{array}$ & $\begin{array}{c}\text { Estudos } \\
\text { incluí- } \\
\text { dos }\end{array}$ \\
\hline Scielo & 25 & 10 & 00 & 10 \\
\hline Lilacs & 18 & 05 & 00 & 04 \\
\hline Medline & 11 & 01 & 00 & 01 \\
\hline $\begin{array}{l}\text { Ceres: nutrição \& } \\
\text { saúde - UERJ }\end{array}$ & 01 & 01 & 00 & 01 \\
\hline Unirio & 01 & 01 & 00 & 01 \\
\hline TOTAL & 56 & 17 & 00 & 17 \\
\hline
\end{tabular}

A base de dados que obteve a maior quantidade de estudos incluídos na presente pesquisa foi a base Scielo (10), seguida da Lilacs (04), da Medline (01) e da Ceres: Nutrição \& Saúde - UERJ (01) e Unirio (01). Com relaçáo às bases de dados selecionadas, de todas se obtiveram estudos disponíveis no idioma português, correspondendo a $17(100 \%)$ dos estudos selecionados.
No Quadro 2 foram relacionadas as informaçóes sumárias dos estudos incluídos, segundo a codificação determinada para melhor abordagem dos estudos, dispostos em ordem alfabética do primeiro autor.

De acordo com o quadro acima, pôde-se observar que as fontes das publicações selecionadas são variadas, predominando as revistas especializadas de Nutrição (06), seguidas de Pediatria (04), Enfermagem (03), Saúde Materno Infantil (02) e Psicologia e dissertações (02).

Em relação ao período de publicação dos estudos, 05 publicados entre 2002 e 2004, 06 entre 2005 e 2007, 04 em 2009 e 02 em 2010. Estes dados demonstram que as pesquisas na área da saúde, em especial, sobre a alimentação infantil estáo em um ritmo crescente, o que retrata a preocupação dos profissionais de saúde em fornecer subsídios ao conhecimento científico para a área.

$\mathrm{Na}$ busca por compreender melhor a temática de práticas educativas dos profissionais de saúde durante a alimentaçáo infantil nos primeiros dois anos de vida, considerou-se necessário realizar uma análise cautelosa do conteúdo das produçóes científicas selecionadas, iniciando primeiramente pela exposiçáo e, posteriormente, análise dos objetivos de cada estudo.

A análise dos objetivos dos estudos resultou em alguns pressupostos relacionados às práticas dos profissionais de saúde durante a alimentaçáo infantil nos primeiros anos de vida. São eles:

- Papel dos profissionais de saúde perante a mulher que vivencia o processo da amamentaçáo;

- Possíveis transformaçóes de conhecimentos, atitudes e práticas de pediatras e nutricionistas após realizar um Curso Integrado de Aconselhamento em Alimentaçáo Infantil;

- Introdução de alimentos complementares de crianças menores de dois anos e características socioeconômicas das mães;

- Recomendações saudáveis da alimentação de crianças menores de dois anos e responsabilidades do profissional de saúde;

- Desmame precoce e características socioeconômico-culturais das mães;

- Orientaçôes atuais sobre a alimentação complementar de crianças em aleitamento materno e contribuiçóes do profissional de saúde;

- Investigação da alimentaçáo complementar de crianças menores de dois anos; 
- Análise da alimentaçáo complementar no primeiro ano de vida;

- Fatores associados à ocorrência do desmame precoce;

- Vivência das mães ao introduzir alimentos complementares na dieta dos lactentes;

- Transição alimentar de crianças entre cinco e oito meses e as influências das avós das crianças e dos enfermeiros;

- Práticas alimentares saudáveis e os desafios no campo da saúde;

- Investigação da alimentação complementar no primeiro ano de vida;

- Cuidado materno ribeiro e a influência do profissional da saúde;

- Introduçáo precoce de alimentos complementares e fatores associados;
- Experiências vivenciadas pelas mulheres mães durante o desmame;

- Proteção da amamentação e do aleitamento exclusivo contra a diarreia nos menores de seis meses.

Por sua vez, a literatura dos pressupostos possibilitou a construção de quatro temas de análise ou categorias de estudo:

- Recomendações de uma alimentação complementar saudável para crianças menores de dois anos e seus benefícios;

- Introdução precoce de alimentos complementares e fatores associados;

- Desmame vivenciado pelas mães e a influência dos profissionais de saúde;

- Atuaçáo dos profissionais de saúde durante a alimentação no primeiro ano de vida.

Quadro 2 - Estudos incluídos, segundo a codificação determinada e dados de publicação.

\begin{tabular}{|c|c|c|c|c|}
\hline $\begin{array}{l}\text { Código do } \\
\text { estudo }\end{array}$ & $1^{\circ}$ autor & Fonte & Título & Ano \\
\hline E1 & Araújo RMA & Scielo & $\begin{array}{l}\text { Aleitamento materno: o desafio de compreender a } \\
\text { vivência. }\end{array}$ & 2007 \\
\hline E2 & Bassichetto KC & Lilacs & $\begin{array}{l}\text { Aconselhamento em alimentação infantil: um estudo } \\
\text { de intervenções. }\end{array}$ & 2009 \\
\hline E3 & Corrêa EN & Lilacs & $\begin{array}{l}\text { Alimentação complementar e características mater- } \\
\text { nas de crianças menores de dois anos de idade em } \\
\text { Florianópolis (SC). }\end{array}$ & 2009 \\
\hline E4 & Dias MCAP & Lilacs & $\begin{array}{l}\text { Recomendações para alimentação complementar de } \\
\text { crianças menores que dois anos. }\end{array}$ & 2010 \\
\hline E5 & Escobar AMU & Scielo & $\begin{array}{l}\text { Aleitamento materno e condições socioeconômico- } \\
\text {-culturais: fatores que levam ao desmame precoce. }\end{array}$ & 2002 \\
\hline E6 & Monte CMG & Medline & $\begin{array}{l}\text { Recomendações para alimentação complementar da } \\
\text { criança em aleitamento materno. }\end{array}$ & 2004 \\
\hline E7 & Oliveira LPM & Scielo & $\begin{array}{l}\text { Alimentação complementar nos primeiros dois anos } \\
\text { de vida. }\end{array}$ & 2005 \\
\hline E8 & Parada CMGL & Scielo & $\begin{array}{l}\text { Práticas de alimentação complementar em crianças } \\
\text { no primeiro ano de vida. }\end{array}$ & 2007 \\
\hline E9 & Ramos W & $\begin{array}{l}\text { Ceres: Nutrição } \\
\text { \&Saúde }\end{array}$ & $\begin{array}{l}\text { Aleitamento materno, desmame e fatores associa- } \\
\text { dos. }\end{array}$ & 2007 \\
\hline E10 & Salve JM & Scielo & $\begin{array}{l}\text { Representações sociais de mães sobre a introdução } \\
\text { de alimentos complementares para lactentes. }\end{array}$ & 2009 \\
\hline E11 & Santos CS & Scielo & $\begin{array}{l}\text { Fatores que interferem na transição alimentar de } \\
\text { crianças entre cinco e oito meses: investigação em } \\
\text { Serviço de Puericultura do Recife, Brasil. }\end{array}$ & 2007 \\
\hline E12 & Santos LAS & Scielo & $\begin{array}{l}\text { Educação alimentar e nutricional no contexto da } \\
\text { promoção de práticas alimentares saudáveis. }\end{array}$ & 2005 \\
\hline E13 & Silva LP & Scielo & $\begin{array}{l}\text { Práticas de alimentação complementar no primeiro } \\
\text { ano de vida e fatores associados. }\end{array}$ & 2010 \\
\hline E14 & Silva RF & Unirio & $\begin{array}{l}\text { Valores culturais que envolvem o cuidado materno } \\
\text { ribeirinho: subsídios para a enfermagem. }\end{array}$ & 2009 \\
\hline
\end{tabular}




\begin{tabular}{|l|l|l|l|l|}
\hline E15 & Simon VGN & Scielo & $\begin{array}{l}\text { Introdução de alimentos complementares e sua rela- } \\
\text { ção com variáveis demográficas e socioeconômicas, } \\
\text { em crianças no primeiro ano de vida, nascidas em } \\
\text { Hospital Universitário no município de São Paulo. }\end{array}$ & 2003 \\
\hline E16 & Sonego J & Scielo & $\begin{array}{l}\text { Experiência do desmame entre mulheres de uma } \\
\text { mesma família. }\end{array}$ & 2004 \\
\hline E17 & Vieira GO & Lilacs & Alimentação infantil e morbidade por diarreia. & 2003 \\
\hline
\end{tabular}

Recomendaçóes de uma alimentação complementar saudável para crianças menores de dois anos e seus benefícios

A alimentação complementar é compreendida como a alimentação fornecida no período em que outros alimentos ou líquidos são oferecidos em adição ao leite materno [12]. A OMS recomenda a promoção do aleitamento materno exclusivo até seis meses de idade e a introduçáo de alimentos complementares adequados a partir dessa idade [12]. Até os seis meses de vida o leite materno exclusivo é suficiente para satisfazer as necessidades nutricionais da criança, além de favorecer a proteção contra doenças. Após essa idade, a inclusão dos alimentos complementares no esquema alimentar da criança tem o objetivo de elevar, principalmente, as quotas de energia e micronutrientes, mantendo-se o aleitamento ao peito até 12 ou 24 meses de idade da criança. Permitindo assim, o bom desenvolvimento físico, neurológico e motor da criança [13].

Segundo Parada, Carvalhaes e Jamas [14], durante a introduçáo de alimentos complementares aos seis meses de vida da criança, os mesmos devem ser preparados sob a forma de papas, purês de legumes, cereais ou frutas. A partir dos oito meses, podem ser oferecidos os mesmos alimentos preparados para a família, desde que amassados, desfiados, picados ou cortados em pedaços pequenos. Recomenda-se o uso de copos para oferecer água ou outros líquidos e dar os alimentos semissólidos e sólidos com prato e colher.

De acordo com Correa et al. [3], o leite materno é inquestionavelmente o melhor alimento nos primeiros meses de vida e seus principais benefícios incluem: proteção das vias respiratórias e do trato gastrintestinal contra doenças infecciosas, ganho de peso adequado, livre de contaminação, proteçáo imunológica, adaptação ao metabolismo da criança, além de estimular o vínculo afetivo entre mãe e filho. A prática de aleitamento materno poderia prevenir $13 \%$ das mortes de crianças menores de cinco anos. Além disso, o estudo de Monte e Giuglian [5] afirma que aleitamento materno exclusivo reduz o risco de asma, previne a morbimortalidade na infância, incluindo desnutriçáo e sobrepeso e parece proteger contra o aparecimento do diabetes melito tipo I. Ao contrário, o leite de vaca (antes dos 4 meses) pode ser um importante determinante dessa doença e pode aumentar seu risco de aparecimento em 50\%.

Vieira, Silva e Vieira [14] revelam em seu estudo que o aleitamento exclusivo conferiu uma forte proteçáo contra óbitos por diarreia e que o aleitamento predominante ou a ausência dele estiveram associados ao risco de doenças infecciosas, respiratórias e de diarreia. Concluíram que houve um aumento dessa chance para $82,0 \%$ quando comparadas as crianças menores de seis meses que náo mamavam com as que mamavam exclusivamente. Ramos e Ramos [15] também apontaram em seus estudos que o aleitamento materno nos primeiros seis meses assegurou níveis mais elevados de hemoglobina e que esses níveis declinavam quando o aleitamento artificial era adotado, sendo compatíveis com anemia.

Pode-se verificar a amplitude de visóes de cada autor sobre a alimentação infantil, bem como a importância de seus benefícios quando oferecida de forma satisfatória. Podemos então dizer que é fundamental a orientação por parte dos profissionais de saúde em aconselhar as mães em oferecer uma nutrição adequada para seu filho, com o propósito de torná-lo um adulto saudável [2].

\section{Introduçáo precoce de alimentos complementa- res e fatores associados}

A introdução precoce dos alimentos complementares com frequência aumenta a vulnerabilidade da criança a diarreias, infecçóes e desnutrição. A consequência imediata da má-nutrição durante esse período é o aumento da morbimortalidade e atraso no desenvolvimento mental e motor [16]. 
Correa et al. [3] em seu estudo verificou que $80 \%$ das crianças menores de dois anos receberam fruta, $77,5 \%$ receberam suco natural associado ao aleitamento materno e $36,8 \%$ receberam leite modificado, em substituição ao aleitamento materno, antes de completarem seis meses de idade. A análise identificou que as mães com menor grau de escolaridade e que trabalhavam fora de casa apresentaram mais chance de introduzir precocemente alimentos aos seus filhos.

Em um estudo realizado por Simon [17], observou-se na verificação da idade de introdução de alimentos de crianças nascidas em Hospital Universitário do Município de São Paulo, que a introdução de água ou chá, leite não materno, frutas, verduras e legumes, cereais e tubérculos foram com menores de 6 meses. Foram verificadas associaçôes estatisticamente significativas entre escolaridade materna, renda familiar, trabalho materno e introdução de alguns alimentos.

$\mathrm{Na}$ pesquisa realizada por Salve e Silva [18] evidenciou-se que a época de introdução do primeiro alimento variou de 25 a 60 dias de vida do bebê para água e chá, de 10 a 150 dias de vida para a fórmula artificial, de 120 a 150 dias para o leite UHT integral e de 120 a 165 dias de vida para os alimentos da família. A média de idade em que a criança recebeu o primeiro alimento diferente do leite materno foi de 80,8 dias de vida.

Já Santos, Lima e Javorski [19] constataram em seu estudo que $79,2 \%$ das crianças entre cinco e oito meses não se adequavam às normas do Ministério da Saúde quanto à transição alimentar. As mães apontaram, como principais motivos: recusa da criança $(23,5 \%)$; interferência da avó (19\%); praticidade do preparo/oferecimento do mingau em relação à alimentação salgada $(17,7 \%)$.

Concluiu-se por meio dos estudos analisados, que a grande maioria das crianças na faixa etária em estudo não recebe uma alimentação saudável. Ademais, diversos fatores prejudicam a oferta do aleitamento materno exclusivo até o sexto mês de vida da criança e, consequentemente, a introdução precoce de alimentos complementares. Nesse sentido, percebe-se a importância da intervenção dos profissionais de saúde na melhoria dos indicadores de amamentaçáo exclusiva até os seis meses de vida da criança e na orientação sobre a oferta de uma alimentação saudável.

\section{Desmame vivenciado pelas máes e a atuaçáo dos profissionais de saúde}

Muitas mulheres, embora considerem o leite materno a melhor opção alimentar para o filho, não amamentam. Mesmo aquelas que se submetem à rotina assistencial, estabelecida pela política estatal como base para o êxito na amamentação, costumam desmamar seus filhos antes do quarto mês de vida. Apesar de as mães valorizarem o leite materno, não se sentem seguras a ponto de adotá-lo como único alimento durante o período em que ele é indicado [20].

Vários estudos realizados no Brasil procuraram calcular a mediana do aleitamento materno e do aleitamento materno exclusivo, e apontaram que ambas ficaram inferiores ao que se é recomendado pelo Ministério da Saúde [15].

Diversos fatores estão associados à ocorrência do desmame precoce: mães primíparas, o uso de chupeta, hospital de nascimento, trabalho materno, nível socioeconômico, grau de escolaridade da mãe, idade da mãe, urbanização, condiçôes de parto, incentivo do cônjuge e de parentes e intenção da mãe de amamentar [21]. Para Sonego et al. [22], em seu estudo, o desmame acontece em razáo de uma nova gestação, idade da criança, doença da mãe ou do filho e recusa do peito pela criança. Verificou-se que o desmame pode ser tranquilo para algumas mulheres, enquanto para outras é acompanhado de sofrimento.

De acordo com uma pesquisa realizada por Escobar et al. [21], numa amostra de 599 crianças, a idade média do desmame foi de 3,3 meses, e $75,9 \%$ das mães suspenderam a amamentação sem orientação médica. 38,9\% referiram que o leite era "fraco", ou "secou" ou que a criança "largou" o peito.

Corrêa et al. [3] revelaram em seu estudo transversal com 516 mães de crianças com menos de dois anos de idade que dentre as crianças menores de dois anos de idade apenas $28,7 \%$ haviam recebido aleitamento materno exclusivo até os seis meses e, dentre as crianças que estavam com menos de seis meses no momento da pesquisa, apenas $49,6 \%$ estavam recebendo aleitamento materno exclusivo.

Oliveira et al. [4] observaram em seu estudo transversal, com amostra constituída de 724 crianças, que o desmame é praticado precocemente. O consumo de leite materno declina expressivamente a partir dos seis meses de idade, e é substituído pelas fórmulas à base de leite em pó integral, espessante e açúcar. 
Já em outro estudo realizado por Silva [23], com mulheres-mães na comunidade ribeirinha de Vila Nova Maringá, constatou-se que o desmame completo costuma ocorrer na comunidade entre o primeiro e o segundo ano de vida da criança. A mudança da dieta é gradual, de líquido, pastoso a sólido. Uma das mães explica que o intestino da criança, após o desmame, ainda é "fraco" e merece essa mudança de dieta.

Segundo Sonego et al. [22], no que diz respeito à atuaçáo dos enfermeiros no processo de desmame, estes precisariam estar disponíveis às famílias, prestando apoio para fortalecê-las no enfrentamento das atividades diárias relacionadas à saúde. Escobar et al. [21] reforçam que o profissional de saúde também é importante no incentivo ao aleitamento materno, apoiando e instruindo a nutriz, acompanhando o pré-natal cuidadoso, formando grupos de gestantes, e oferecendo alojamento conjunto, durante a puericultura e na promoçáo de campanhas de incentivo ao aleitamento. Afinal, à medida que se conhecem os motivos que possam contribuir com o desmame precoce, pode-se atuar melhor no sentido de prevençáo desses fatores de forma mais direcionada e, portanto, mais eficaz.

Para Silva [23], o profissional enfermeiro envolvido com o cuidado da saúde materno-infantil deve ficar atento a um detalhe: o de que existem náo só culturas diferentes daquela por ele vivenciada, mas conceitos sobre a amamentaçáo igualmente diferentes dos preconizados pelo modelo biomédico. O enfermeiro, desta forma, precisa compreender a mulher para, só então, ajudá-la no cuidado dirigido aos filhos.

\section{Práticas educativas dos profissionais de saúde}

Os serviços e profissionais de saúde têm sido alvo de discussóes sobre atitudes e práticas diante da promoção da alimentaçáo infantil. Constantemente, ambos são responsabilizados pelo sucesso dessa prática, cuja atuação na promoção, informação e apoio às mulheres estende-se da atenção ao pré-natal, ao parto, ao puerpério imediato e à puericultura [20].

A valoração dos profissionais de saúde é realçada em documento da 55a Assembleia Mundial de Saúde, que aponta a necessidade de as máes receberem apoio especializado, ou seja, de alguém capaz de ajudá-las a iniciar e manter práticas apropriadas de alimentação da criança, bem como prevenir e ajudar a superar dificuldades [20].

$\mathrm{Na}$ prática, os profissionais de saúde apresentam alguma dificuldade para manter-se atualizados em relação à alimentação infantil, especialmente pela falta de investimentos da rede pública em treinamentos que enfoquem a melhoria do desempenho em aconselhamento [23].

Para orientar as mães/cuidadores na escolha dos alimentos complementares, o profissional de saúde deve conhecer o conteúdo nutricional dos alimentos locais e sua utilização para a alimentação infantil. Quando necessário, deve consultar tabelas locais de composição de alimentos [5].

Para Salve e Silva [18] o profissional de saúde também deve reconhecer os aspectos simbólicos e culturais que envolvem a alimentação da criança, permitindo maior proximidade entre a realidade vivenciada pelas máes. Dessa forma, é possível auxiliá-las a melhor interpretar os comportamentos da criança, visando, por fim, atuar de maneira mais efetiva nas questóes da alimentação infantil.

Santos, Lima e Javorski [19] revelaram em sua pesquisa a percepção das mães acerca da qualidade das orientaçóes fornecidas pelo enfermeiro, com relação à dieta de transição. Para a maioria (70,5\%), o enfermeiro ressaltou a importância dos alimentos complementares oferecidos à criança. Observou-se que 97,4\% das mães esclareceram suas dúvidas e receberam orientaçóes por escrito, além das verbais, e $94,8 \%$ não tinham dúvidas, após a consulta. Apenas 2,6\% das mães afirmaram não ter tido oportunidade de esclarecer dúvidas, durante a consulta.

Segundo Escobar [21], ao contrário do esperado, o acompanhamento da criança pelo posto de saúde não influenciou o tempo de amamentação. Assim, as açôes educativas no sentido de preconizar a importância do aleitamento materno deveriam ser enfatizadas com mais vigor e insistência pelos profissionais de saúde. Entretanto, na mesma pesquisa, a maioria dos entrevistados sabia da importância do leite materno ( $92 \%)$, mas não realizaram as práticas alimentares da criança de forma saudável.

Santos, Lima e Javorski [19], em sua pesquisa formada por 101 mães de crianças entre cinco e oito meses, constataram que $97,4 \%$ das mães afirmaram receber as orientaçóes verbais e escritas no serviço. No entanto, os resultados demonstrados não apontaram uma adequaçáo alimentar às nor- 
mas do Ministério da Saúde. Diante desse cenário, o pesquisador supracitado considera que durante o processo de comunicação poderá ocorrer que: as pessoas ouvem, mas não compreendem; ouvem e pensam que compreendem, náo executando as orientaçôes de maneira certa ou transmitindo a outrem de maneira errada; ouvem e compreendem, mas não ficam convencidas e não modificam seus hábitos. Dessa maneira a comunicação será considerada ineficaz, embora seja realizada pelo enfermeiro durante as consultas. $\mathrm{Na}$ mesma amostra estudada, o enfermeiro e a avó foram os principais orientadores da transiçáo alimentar, com $77 \%$ e $16 \%$, respectivamente. Entretanto, apenas $20,8 \%$ das crianças apresentaram um padrão alimentar adequado, segundo as orientaçóes do Ministério da Saúde. A mãe, principal responsável pelos cuidados da criança, sofreu influências do seu ambiente familiar, sobretudo da avó e da sociedade em que está inserida.

Portanto, é necessário não só valorizar a puericultura, mas, também, focar as avós e os familiares próximos da criança no sentido de oferecer a eles informaçốes importantes sobre a complementação alimentar que, consequentemente, irá refletir em sua vida adulta.

Monte e Giugliani [5] concluem em seu estudo que a alimentação complementar adequada à criança em aleitamento materno é crítica para o ótimo crescimento e desenvolvimento da criança. Portanto, cabe aos profissionais de saúde repassar efetivamente às mães/cuidadores as novas recomendações para a promoção da alimentação complementar saudável da criança amamentada. Cabe aos governos propiciar as condiçóes adequadas para essa promoção.

\section{Conclusão}

Os resultados deste estudo mostraram que o aleitamento materno é substituído precocemente por outros alimentos interferindo na nutrição infantil saudável. Além disso, a introdução de novos alimentos na dieta das crianças não segue as recomendaçóes do Ministério da Saúde. Observou-se também que há grande carência de ferro, nutrientes, proteínas, vitaminas e minerais na composição alimentar das crianças.

Sugere-se, portanto que para alcançar o sucesso de uma alimentação infantil saudável é necessário o reconhecimento pelos profissionais de saúde dos aspectos simbólicos e culturais, que envolvem a alimentação da criança, bem como ajudá-los a interpretá-los. A identificação e a valorização destes aspectos permitiráo maior proximidade entre os profissionais da área de saúde e a realidade vivenciada pelas mães e outros cuidadores. Nesse sentido, espera-se a construção de novos olhares sobre a alimentação nos primeiros dois anos de vida no intuito de promover uma alimentaçáo infantil saudável.

\section{Referências}

1. Fujimori E, Ohara CVS. Enfermagem e a Saúde da Criança na Atenção Básica. $1^{a}$ ed. São Paulo: Manole; 2009. 548p.

2. Brasil. Ministério da Saúde. Secretaria de Atenção à Saúde. Departamento de Atenção Básica. Saúde da criança: Nutrição Infantil: Aleitamento Materno e Alimentação Complementar. Brasília: Ministério da Saúde; 2009. p.112.

3. Corrêa EM, Corso ACT, Moreira EAM. Alimentação complementar e características maternas de crianças menores de dois anos de idade em Florianópolis (SC). Rev Paul Pediatr 2009;27(3):258-64.

4. Oliveira LPM, Assis AMO, Pinheiro SMC, Prado MS, Barreto ML. Alimentação complementar nos primeiros dois anos de vida. Rev Nutr 2005;18(4):459-69.

5. Monte CMG, Giuglian E. Recomendaçóes para alimentação complementar da criança em aleitamento materno. J Pediatr 2004;80(5):131-41.

6. Santos LAS. Educaçáo alimentar e nutricional no contexto da promoção de práticas alimentares saudáveis. Rev Nutr 2005;18(5):681-92.

7. Polit DF, Beck CT, Hungler BP. Fundamentos de pesquisa em enfermagem: métodos, avaliação e utilização. Traduzida por Thorell A. $5^{\mathrm{a}}$ ed. Porto Alegre: Artmed; 2004. p. 114.

8. Broome ME. Análises integrativas de literatura para o desenvolvimento de conceitos. In: Rodgers BL, Knafl KA. Desenvolvimento de conceitos em enfermagem: fundamentos, técnicas e aplicaçóes. Philadelphia: WB Saunders 2000. p.231-50.

9. Campos RG. Burnout: uma revisão integrativa na enfermagem oncológica Ribeirão Preto: Universidade de São Paulo, Escola de Enfermagem de Ribeirão Preto; 2005. 158p.

10. Beya SC. Elaboração de diretrizes para a prática clínica como uma abordagem para a prática baseada em evidências. AORN Journal 1998;67(5):1037-38.

11. Ganong LH. Comentários de pesquisa integrativa em Enfermagem. Pesquisa em Enfermagem e Saúde 1987;10:1-11.

12. Dias MCAP, Freire LMS, Franceschini SCC. Recomendaçóes para alimentação complementar de crianças menores que dois anos. Rev Nutr 2010;23(3):475-86.

13. Parada CMGL, Carvalhaes MABL, Jama MT. Práticas de alimentaçáo complementar em crianças no primeiro ano de vida. Rev Latinoam Enferm 2007;15(2):282-9. 
14. Vieira GO, Silva LR, Vieira TO. Alimentação infantil e morbidade por diarreia. J Pediatr 2003;79(5):449-54.

15. Ramos VV, Ramos JV. Aleitamento materno, desmame e fatores associados. Ceres: Nutrição \& Saúde 2007;2(1);43-50.

16. Silva LP, Venâncio SI, Marchioni DML. Práticas de Alimentaçáo Complementar no primeiro ano de vida e fatores associados. Rev Nutr 2010;23(6):983-92.

17. Simon VGN, Souza JMP, Souza SB. Introdução de alimentos complementares e sua relação com variáveis demográficas e socioeconômicas, em crianças no primeiro ano de vida, nascidas em Hospital Universitário no município de São Paulo. Revista Brasileira de Epidemiologia 2003;6(1):29-38.

18. Salve JM, Silva IA. Representaçóes sociais de mães sobre a introdução de alimentos complementares para lactentes. Acta Paul Enferm 2009;22(1):43-8.

19. Santos CS, Lima LS, Javorki M. Fatores que interferem na transição alimentar de crianças entre cinco e oito meses: investigação em Serviço de Puericultura do Recife, Brasil. Rev Bras Saúde Matern Infant 2007;7(4):373-80.

20. Araújo RMA, Almeida JAG. Aleitamento materno: o desafio de compreender a vivência. Rev Nutr 2007;20(4):431-8.

21. Escobar AMU, Ogawa AR, Hiratsuka MI, Kawashita MY, Teruya PY, Grisi S, Tomikawa SO. Aleitamento materno e condiçóes socioeconômico-culturais: fatores que levam ao desmame precoce. Rev Bras Saúde Mater Infant 2002;2(3):253-61.

22. Sonego J, Van der Sand ICP, Almeida AM, Gomes FA. Experiência do desmame entre mulheres de uma mesma família. Rev Esc Enferm USP 2004;38(1):341-9.

23. Silva RF. Valores culturais que envolvem o cuidado materno ribeirinho: subsídios para a enfermagem [Dissertação]. Rio de Janeiro: Centro de Ciências Biológicas e da Saúde, Universidade Federal do Estado do Rio de Janeiro; 2009. 100p

24. Bassichetto KC, Réa MF. Aconselhamento em alimentação infantil: um estudo de intervenções. J Pediatr 2008;84(1):75-82. 